\title{
Javé: Onde o Patrimônio se confrontou com o Progresso
}

\author{
Jave: Where the heritage confronted progress
}

\section{Fernando Arnold Lorenzon}

Universidade de Passo Fundo - UPF - Passo Fundo - Rio Grande do Sul - Brasil

Resumo: O presente artigo foi produzido com a intenção principal de se discutir as relações entre o patrimônio histórico e o progresso. Para discutir tal relação foi optado por se fazer uma análise da obra cinematográfica brasileira intitulada Narradores de Javé. O filme conta a história de um pequeno povoado que se vê na iminência de ser inundado pela construção de uma usina hidroelétrica. A partir de pesquisa bibliográfica referente aos conceitos de patrimônio e progresso pretende-se analisar a constante disputa de significados atribuídos ao patrimônio, como bem cultural, histórico e identitário a ser preservado e ao progresso. Este artigo foi organizado de forma a contemplar as discussões referentes ao conflito entre o patrimônio e o progresso sendo que, optamos por iniciar a presentando o filme mencionado e o contexto exibido na obra para que fosse possível problematizar a discussão no decorrer do texto. A partir daí, foi possível evidenciar características de um conflito que nos é comum, uma vez que, são duas forças em constante movimento na sociedade.

Palavras-chave: Cinema. Patrimônio Histórico. Progresso.

Abstract: This article was produced with the main intention of discussing the relationship between heritage and progress. To discuss this relationship has been chosen to do an analysis of Brazilian cinematographic work entitled Narradores de Javé. The filmtells the story ofa small townthat is seenabout to befloodedby the construction ofa hydroelectric plant.From bibliographic research related to heritage and progress concepts we intend to analyze the constant dispute of meanings attributed to heritage, as well cultural, historical and identity to be preserved and progress. This article was organized to consider the discussions related to the conflict between heritage and progress and, we chose to start showing the mentioned film and the context displayed in the work to make it possible to problematize the discussion throughout the text. From there, it became clear characteristics of a conflict that is common to us, as are two forces in constant movement in society.

Keywords: Cinema. Historical Heritage. Progress. 


\section{Introdução}

Quando olhamos para nossa sociedade, é possível perceber que ocorre, nos mais diversos níveis, uma constante busca pelo crescimento, evolução, melhora, em suma, uma busca constante pelo progresso no sentido de se "andar em frente". Este progresso refere-se aos mais diversos âmbitos da sociedade, podendo ser financeiro, cultural, tecnológico, infraestrutural ou os mais diversos meios ou formas de se melhorar a vivência, a convivência e a sociedade como um todo.

Nas instituições de ensino há uma nova tendência, principalmente nas aulas de história e nos programas educacionais que são a ênfase no patrimônio cultural nas aulas normais e nas oficinas dos programas criados pelo governo como por exemplo, o Programa Mais educação e sua oficina de Educação Patrimonial. Dentro destes ambientes de ensino acaba ocorrendo o conflito entre o patrimônio e o progresso, uma vez que, a ênfase dos currículos é na preservação e a preservação muitas vezes implica em deter este aclamado progresso.

Esta situação é bem exemplificada na obra assistida e utilizada para análise do confronto entre os dois agentes antagônicos analisados.

\section{Narradores de Javé: Agentes em conflito}

O filme brasileiro Narradores de Javé ${ }^{1}$ é uma obra cinematográfica que nos possibilita pensar as relações possíveis entre o patrimônio histórico e a noção de progresso no mundo moderno. A película relata a história de um pequeno povoado localizado em uma região do sertão baiano chamado Javé. Com o advento de novas obras do governo federal, dentre elas um grande número de usinas hidrelétricas, o pequeno vilarejo se encontra na iminência de ser atingido pelas obras de uma destas usinas, ou seja, está prestes a ser inundado em consequência do represamento dos rios da região.

Frente a esta terrível situação, o povo de Javé se reúne para decidir que atitude tomar para que 0

\footnotetext{
${ }^{1}$ Filme brasileiro lançado em 2003 e dirigido por Eliane Caffé.
}

problema seja resolvido e suas terras sejam salvas uma vez que, as únicas formas de registro histórico existentes ali são os versos cantados pelas primeiras pessoas que chegaram ao local há muitos anos e construíram a pequena Vila. Não há nenhum documento escrito que comprove quem são os proprietários do local e os versos foram passados aos descendentes unicamente de forma oral.

De acordo com o organizador da reunião de moradores, a única forma de salvar a localidade é comprovar que ali existe algo de grande importância histórica, algo que possa ser tombado como patrimônio histórico e assim impeça a inundação e a consequente destruição de seus lares. Com esta ideia, os moradores decidem que o ideal seria preparar um documento que conte todos os acontecimentos do lugar provando assim que ali existe um patrimônio que deve ser preservado e desta forma proteger o local do desastre que se aproxima, porém, aí aparece outro obstáculo: como produzir este documento escrito se ninguém no povoado sabe escrever?

Para fazer esta tarefa, os moradores vão em busca do carteiro local, que a muito tinha sido expulso da vila por começar a escrever cartas contando histórias imaginadas por ele mesmo enviando-as para os arredores a fim de manter seu emprego visto que, em um local onde ninguém é alfabetizado, logo seu trabalho estaria extinto do povoado. Apesar disso, o carteiro é o único que sabe escrever, portanto o único que pode ouvir os moradores locais e escrever as histórias e memórias do Vale de Javé e talvez salvar o vilarejo da inundação.

O filme trata, de forma cômica, a relação entre o progresso e o patrimônio, na medida em que o patrimônio é utilizado como meio de formação e afirmação de uma identidade que se encontra ameaçada pelo advento do progresso. Quando pensamos em progresso, normalmente nos deparamos com ideias de evolução, caminhar em frente, renovação, tanto no campo da produção de conhecimento (ciências) quanto no próprio modo de vida dos seres humanos. É comum pensarmos o progresso como uma forma de crescimento intelectual 
e físico no que se refere diretamente aos seres humanos, e tecnológico científico, no que se refere a objetos métodos e técnicas que interferem na vida humana. Exemplificando esta ideia de progresso Paolo Rossi nos diz que:

Para transpor o oceano e descobrir um novo mundo foi necessária a descoberta da bússola. Ao lado da invenção da imprensa e da pólvora explosiva, a descoberta da bússola e as viagens oceânicas revolucionaram a história do mundo; modificaram a posição do homem. Nenhum império, nenhuma escola filosófica, nenhuma estrela tiveram sobre a história humana um efeito maior do que tiveram aquelas invenções. São elas que tornaram as filosofias dos antigos não mais utilizáveis. (ROSSI, 2000, p.24)

Na afirmação de Rossi é perceptível que a noção de progresso está ligada a aspectos científicos, econômicos e tecnológicos, mas, principalmente está impregnada com a concepção de que se deve deixar o passado para trás. Neste sentido, as inovações concebidas em todos os campos surgiram para que não mais se utilizassem as "filosofias" dos antigos sendo que, dentro desta ideia de filosofia podemos incluir todas as novas produções em todas as áreas das ciências, uma vez que estas, de acordo com esta visão acerca do progresso, vêm para fazer a humanidade manter seus olhos no horizonte e seguir sua caminhada até lá.

Ao problematizarmos a preservação do patrimônio diante das mudanças proposta pelo progresso coloca-se a seguinte questão: De que forma preservar o patrimônio frente aos desafios do progresso?

Ao acompanharmos as transformações do conceito de patrimônio, observamos que este está articulado aos contextos das diferentes temporalidades históricas que vem à tona quando identidades são postas em cheque. Cita-se como exemplos a formação dos Estados Nacionais na Europa, quando a noção de patrimônio histórico, através da educação, serviu para a construção da identidade dos cidadãos que compunham estes estados. Também no mundo pós-guerras do século XX, o continente Europeu se viu forçado a (re)inventar tradições e costumes com vias a reestruturar as identidades que haviam sido fragmentadas. No caso do Brasil, podemos mencionar o advento do Estado Novo com o presidente Getúlio Vargas onde foram criadas diversas instituições com fins de se resgatar 0 patrimônio histórico e cultural relacionadas à identidade que se queria construir para o país naquela época.

De acordo com Canclini (1994), as construções em torno do conceito de patrimônio sofrem influência permanente do contexto social, histórico, econômico e da temporalidade em que ocorrem, portanto, aquilo que se entende por patrimônio nacional muda de acordo com as épocas. Isto demonstra que, mesmo existindo suportes concretos e contínuos do que se concebe como nação (o território, a população, seus costumes, etc.), em boa parte o que se considera como tal é uma construção imaginária (CANCLINI, 1994, p. 98).

O filme Narradores de Javé mostra uma situação onde ocorre um confronto do progresso com o patrimônio local, sendo o progresso representado pela construção da usina hidrelétrica e o patrimônio pelas memórias locais que se manifestam nos relatos orais dos moradores que buscam a salvação do Vale de Javé diante da construção da hidroelétrica que ameaça varrê-los do lugar em que residem.

$\mathrm{Na}$ situação apresentada, a preservação do patrimônio se manifesta como uma forma de resistência da comunidade local, que recorre as histórias contadas pelos mais velhos aos mais novos e destes para a geração seguinte, por vezes com acréscimos e exageros por parte de quem conta. Conforme Bourdieu (1989) só nos é possível tecer representações acerca do que realmente aconteceu considerando que estamos temporalmente afastados do fato puro e temos a tendência de construir explicações fundadas sobre variáveis não imediatamente notadas pelos indivíduos, cujas percepções são deturpadas política, social e institucionalmente pela família, pela escola, pelo Estado (BOURDIEU, 1992, p. 186).

Neste sentido, mesmo os moradores de Javé, contam as histórias que eles mesmos ouviram de 
seus antepassados, estando gerações afastados do fato real. Considerando o autor citado, não nos é possível construir nada além de representações de uma realidade temporalmente distante e ainda assim, carregada de transformações sofridas com o passar do tempo e cheia de influências sociais, políticas, econômicas e culturais.

Quando observamos o uso do patrimônio pelo olhar do povo do Vale de Javé, vemos que este se manifesta como uma tabua de salvação para sustentar uma identidade que está em vias de ser destruída pelo avanço das grandes obras em prol do progresso. De acordo com Stuart Hall, observa-se o que se pode chamar de uma crise identitária, que é vista como parte de um processo mais amplo de mudança, que está deslocando as estruturas e processos centrais das sociedades modernas e abalando os quadros de referência que, até então, davam aos indivíduos uma ancoragem estável no mundo social (HALL, 2001).

Neste caso, inicia-se dentro do vilarejo uma disputa entre os moradores relacionada à qual é a versão oficial da história do povoado e quem são seus "verdadeiros" fundadores. Observa-se então, que as definições de patrimônio dizem respeito às diferentes atribuições de significado, que variam de acordo com as múltiplas representações de diferentes sujeitos sociais, qual é aquela considerada verdadeira frente a tantas representações de acordo com seus múltiplos interesses.

Esta disputa de significados se dá principalmente quando os moradores contam a história da fundação do povoado, envolvendo questões de gênero que resultam em uma versão masculina e outra feminina da fundação do povoado e questões referentes a heroicidade ou não do fundador e da posse e herança das terras. Neste momento fica perceptível que o patrimônio é um campo de conflito que envolve a disputa de significados entre um discurso hegemônico e o discurso local dos moradores de Javé, que pretendem contar a "verdadeira" história da vila. Neste caso, conforme Ruben Oliven, "O regionalismo pode ser encarado como um campo de disputas no qual grupos com diferentes posições e interesses se enfrentam". Oliven apropriando-se de Bourdieu argumenta que as lutas a propósito da identidade regional se constituem num caso particular de lutas de classificação, lutas pelo monopólio de impor a definição legítima da divisão do mundo social (OLIVEN, 1992, p. 19).

Apesar de ser uma vila com uma população extremamente pequena, começam a ocorrer disputas e enfrentamentos entre pessoas com posicionamentos e interesses diferentes ao se reproduzirem as histórias da Vila de Javé. Aparecem tentativas de se estabelecer uma hegemonia sobre o discurso oficial, hegemonia esta que se configura subordinada de acordo com Gramsci

1) do consenso espontâneo dado pelas grandes massas da população à orientação impressa pelo grupo fundamental dominante à vida social, consenso que nasce historicamente do prestígio (e portanto, da confiança) obtida pelo grupo dominante por causa de sua posição e de sua função no mundo da produção; 2) do aparelho de coerção estatal que assegura legalmente a disciplina dos grupos que não consentem, nem ativa nem passivamente, mas que é constituído para toda a sociedade na previsão dos momentos de crise no comando e na direção, nos quais desaparece o consenso espontâneo. (GRAMSCI, 2004, p. 21)

Pode-se ainda problematizar o filme por meio de dois elementos: a coerção e o consenso. A coerção é representada nas cenas em que o carteiro, encarregado de escrever as histórias narradas pela população, sofre pressão de algumas pessoas do local para que registre os fatos de acordo com a versão por eles contada (esta pressão aparece na forma de ameaças e subornos), montando assim a parte coercitiva do aparelho hegemônico. Já o elemento consenso aparece quando toda a população consente em criar um documento escrito com sua história.

No filme Narradores de Javé a preservação do patrimônio está diretamente articulada à preservação da identidade local dos moradores de Javé e salvação de suas terras e posses, que constituem o sentimento de pertença daquela comunidade formando assim a sua identidade. 
Apesar destes diferentes usos do patrimônio e de sua invocação em momentos de crise, se considerarmos a definição de progresso dada por Paolo Rossi, não temos aí um aparato de construção de identidade, mas sim um obstáculo, uma barreira, algo que impede de "deixarmos o antigo para trás", que atrapalha o desenvolvimento humano. Nestes termos, o patrimônio é uma invocação do antigo, quase que um retrocesso da história e um obstáculo ao avanço do progresso.

No filme, o fato dos moradores de Javé resolverem (re)construir seu patrimônio histórico para tentar salvar a localidade de uma destruição iminente com a inundação do Vale representa um golpe de resistência ao progresso, representado pela construção da usina hidrelétrica conformando, dentro das definições apresentadas acerca dos conceitos de patrimônio e de progresso, uma relação antagônica de difícil arbitragem.

Conforme se desenrola o filme, o progresso aparece como uma prova prática de que a humanidade produziu conhecimento a ponto de ter o poder de dominar e controlar a natureza e os próprios seres humanos sendo que, desta forma, é possível olharmos para o progresso como uma confirmação do desenvolvimento científico e do saber da humanidade. De acordo com Adorno e Horkheimer (2006)

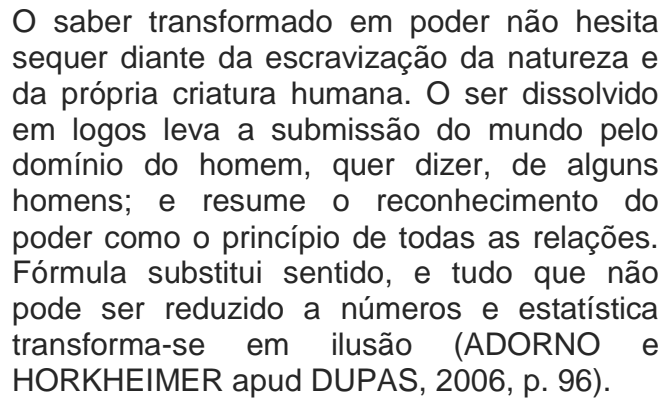

Assim sendo, podemos conceber a ideia de progresso como uma forma de controle do homem sobre a natureza e controle do homem sobre o homem não havendo, nestes termos, espaço para o patrimônio uma vez que este se mostra como uma contrariedade ao progresso. O patrimônio aparece como uma tentativa de se derrubar este controle da natureza e dos homens sobre os homens que se impõe através do progresso. Os discursos acerca da fundação do povoado de Javé rememoram limites e fronteiras naturais das terras do Vale de Javé e são apresentados como obstáculos naturais e históricos ao progresso que deve deixar para trás o que é velho e controlar a natureza. Quando patrimônio histórico e ambiental são articulados conjuntamente, ocorre no filme um desafio ao progresso, uma perda momentânea do controle sobre o que é natural através do que é histórico.

\section{Considerações finais}

Conclui-se que o filme Narradores de Javé nos apresenta o conflito entre patrimônio histórico e o progresso de forma a construir no espectador a esperança de triunfo da população local sobre o progresso que aparece visibilizado na construção da usina hidrelétrica, como uma força que colocará debaixo d'água o povoado do Javé, inundando assim tudo aquilo que se apresenta como antagônico ao progresso. Neste sentido, o progresso se sobrepõe ao antigo que é representado como atrasado. Também se sobrepõe ao meio ambiente, que deve ser controlado e aos seres humanos que em algumas situações também se configuraram como barreiras ao avanço do progresso.

Desta forma, podemos ver no patrimônio algumas tendências referentes ao seu uso. Ele pode ser utilizado como uma ferramenta de salvação pelas mais diversas classes ou grupos sociais para 0 fortalecimento, construção e reconstrução de identidades que se encontrem em crise e também, é um aparato de legitimação de poder, uma vez que, através do patrimônio histórico, é possível se construir bases históricas que vem a afirmar e dar legitimidade a grupos hegemonicamente dominantes. 
Finalmente, quanto as definições de progresso e observando as situações expostas no filme, é possível perceber que o sentido de progresso se constrói dentro de cada situação específica em que está inserido alterando-se temporalmente, socialmente e geograficamente sendo que, estas mudanças não são concomitantes uma a outra. No filme, o progresso aparece de duas formas, de um lado como destruidor do antigo, do pobre, do feio, do velho, e de outro lado, como provas do avanço da humanidade, ou seja, em um mesmo espaço temporal, social e geográfico, temos duas construções dos sentidos do patrimônio.

\section{Referências}

BOURDIEU, Pierre. A Economia das Trocas Simbólicas. 6. ed. São Paulo: Perspectiva, 2007.

BOURDIEU, Pierre. O Poder Simbólico. Rio de Janeiro: Bertrand Brasil, 1989.

CANCLINI, Néstor Garcia. O Patrimônio Cultural e a Construção Imaginária do Nacional. Revista do Patrimônio Histórico e Artístico Nacional. IPHAN, no 23, 1994.

DUPAS, Gilberto. O mito do progresso; ou progresso como ideologia. São Paulo: Unesp, 2006.

GRAMSCI, Antonio. Cadernos do Cárcere: Os intelectuais. O princípio educativo. Jornalistas. 3. ed. Rio de Janeiro: Civilização Brasileira, 2004. Edição e tradução de Carlos Nelson Coutinho com a colaboração de Luiz Sergio Henriques e Marco Aurélio Nogueira. Disponível em: <http://marxismo21.org/wp-

content/uploads/2014/08/Gramsci.pdf>. Acesso em: 22 abr. 2015.

HALL, Stuart. A identidade em questão In: A identidade cultural na pós-modernidade. Tradução Tomás Tadeu da Silva, Guaracira Lopes Louro. 6. ed. Rio de Janeiro: DP\&A, 2001. 103 p. p. 7-22 [Título original do livro: The question of cultural identity.]

OLIVEN, Ruben George. A Parte e o Todo: A Diversidade cultural no Brasil-Nação. Petrópolis: Vozes, 1992.

ROSSI, Paolo. Naufrágios sem espectador: A ideia de progresso. São Paulo: Editora Unesp, 2000. 